\title{
Talent Management: a Philippine State University Graduate School Experience
}

\author{
Riomar Obliopas ${ }^{1, *}$, Dr. Felix Afable ${ }^{2}$ and Jovito Madeja ${ }^{3}$ \\ ${ }^{1}$ Research and Development Services (RDSO), Eastern Samar State University, \\ Philippines; riomaroblioas@gmail.com \\ ${ }^{2}$ Graduate School, Eastern Samar State University, Philippines; butchandmiko@gmail.com, \\ ${ }^{3}$ Research and Development Services (RDSO), Eastern Samar State University, Philippines; jb_madeja@yahoo.com
}

\begin{abstract}
Objective: This paper explored the talent management practices in Eastern Samar State University- Graduate School based on students' and faculty members' experience. Methodology: The study utilized the qualitative research design and employed Colaizzi's Method of Inquiry in analyzing data. Findings: Patterns of responses indicated that "twist in the curricular map" as well as "coaching and mentoring" for thesis writers are some of the best talent management practices for students. "Awards and recognitions" for excellent performance and the "nurture and mentor" culture for faculty have been reported effective strategies of the administration. Application: The study recommends that considerable attention should be placed on faculty engagement since it bridges the gap between retention and productivity of the best faculty in the university.
\end{abstract}

Keywords: Talent Management, Graduate School, State University, Graduate School Management, Philippines

\section{Introduction}

Organizational Talent Management is defined as a special adaptive step taken by an organization to preserve its pool of top talent through creative recruitment, development, and retention of employees. It also denotes an intentional approach to attract, develop and retain people with the right work attitude and abilities required to meet current and future organizational needs. 1

Increased interest in Talent and Talent Management as key management issues has been observed in recent years. Management literature focused on talent management first appeared almost two decades ago. It has become a considerably debated topic in the academic literature and has been a discourse and organizational practice focus. $\underline{\underline{2}}-\underline{6}$

In ${ }^{1}$ posited that in today's society, it has become more and more critical to deal with TM. However, despite the growing interest in TM, ambiguities on what talent management is and how organizations should deal with it or implement it are still evident.

TM literatures are highly conceptual $\underline{5}$ hence, little is known about its practical implementation. Around 2010, records of an increasing number of empirical studies on TM have been observed. There are few empirical studies that examine TM from an employees' perspective ${ }^{\underline{Z}}$ or $\mathrm{TM}$ in public sector organizations ${ }^{-}$that remain underexplored. Qualitative research types were mostly applied while quantitative research was less frequently utilized. Mixed-method studies have been the least present. 9

Today, understanding demographics, empowering technologies and defining talent management have been the struggles of most organizations. While policies on recruitment, retention and replacement are already in the place in most systems, others are struggling with strategic elements of managing talent. For organizations to survive in a highly competitive world, talent management practices serve as a key factor not only in managing the supply and demand of talent to surmount organizational issues and problems but at the same survive for the coming years. Hence, this investigation was prompted in order to provide insights on how the Eastern Samar State University-Graduate School, as the highest academic unit, will be able to propel the organization forward towards the realization of its goals and objectives and at the same

${ }^{*}$ Author for correspondence 
time serve its duty of upholding the highest quality of education expected from it.

\section{Objectives of the Study}

The investigation primarily described the talent management experience of Eastern Samar State University-Graduate School through the eyes of its faculty members and students. Specifically, the study explored the experiences of the graduate school teachers and students on the talent management practices in terms of the following: (1) The shifts in the workforce demographics; (2) Recruitment, Retention, and Promotion; (3) Adaption to the $21^{\text {st }}$ Century Workforce; (4) Talent Evaluation System.

\section{Research Methods}

The study is qualitative in nature as it is deemed appropriate to address the objectives posed for the investigation. It is phenomenological by design for it described the experience of select graduate school faculty and students on the talent management practices of the university. The interview schedule was utilized to obtain the primary data of the investigation and Colaizzi's Method of Inquiry was employed to analyze the data obtained from the participants. This was done by following Colaizzi's Seven-Step Method, as follows: (1) Familiarization; (2) Identifying Significant Statements; (3) Formulating Meanings; (4) Clustering Themes; (5) Developing an Exhaustive Description; (6) Producing the Fundamental Structures; (7) Seeking Verification of the Fundamental Structures.

Since data were obtained from two sources, separate analytical treatments were done. Informed consent was ensured prior to data collection and ethical considerations were observed during the data collection procedure.

\section{Results and Discussion:}

\subsection{Shift in the Workforce Demographics}

The discussion presented proceeds according to the objectives of the study. To answer objective number one, participants were asked about their observations as to how graduate school's administration manages the aging workforce. From the consensus of both participants, it was revealed that there is an excellent "management of the sudden shift of age demographics" in the graduate school as supported by subject assignment to tenured faculty and at the same time recruitment younger breed of professors in the university. This was further described by the participants as "nurturing of young and potential" faculty members who may replace the older generations of professors upon their retirements. This practice indicates that the administration is consistently looking into calibrating the quality of graduate school education through effective management of the pressures imposed by an evidently aging workforce. Further, results signify that administration is visionary for it "considers the projected requirement" of its tenured faculty.

In addition, one of the revealing themes from the analyses shows that the administration provides an updated "assessment of employees' competency sets." This finding justifies the efforts of the administration to provide a balanced evaluation for all faculty members in order to ensure that it has the quality of employees it needs today and in the future.

Further, it was found that in terms of future visions, the management takes into account the "development of succession plans." However, themes also indicated a slight need to "anticipate and plan staffing needs."

\subsection{Recruitment, Retention, and Promotion}

The second objective dwells on the recruitment, retention, and promotion practices of the institution. To address the problem, the teacher- participants were asked as regards the policies on recruitment, retention, and promotion in the graduate school. Patterns of responses revealed a strong policy on the retention of faculty members. It was found that systems of "awards and recognition" are effective determinants of faculty retention and promotion. To some extent, it has played an important role in the recruitment of new faculty members. Consensus indicated that new members of the graduate school were invited to teach on the merit of the previous performance in research and extension. Demographics have also played part in recruitment and retention policies of the unit. It was shown from the responses that due to the age shift in the demographics of the workforce, more and younger faculty are hired to teach at the graduate level. They are not meant to replace older workers but have been viewed as a "succession strategy" of the management. "Enough training for older workers" as well as for younger faculty members was reported. In addition, despite stringency in 
the demands of graduate school work, faculty-participants have also accorded that management is lenient on "flexible work schedule".

On the students' side, patterns revealed one of the best talent management strategies utilized by the administration to ensure the quantity and quality of graduates. It was reported that the "twist in the curricular map" did not only attract enrollees but at the same time improved students' retention and sustained them until completion of their degrees. Stories indicated that the abolition of the policy requiring graduate students to Complete their Academic Requirements before Thesis Writing has attracted more graduate students. At present, the university graduate school has imposed a new policy requiring students to take up Thesis Writing vis-à-vis the subjects Advanced Statistics and Methods of Research alongside their completion of other academic courses.

Coaching and mentoring strategies were also reported helpful especially for those who were under thesis writing. These findings imply that the newly implemented policy of the unit has brought about significant change not only to the curricular map but to the overall attainment of graduate school goals and objectives.

\subsection{Adaption to the $21^{\text {st }}$ Century Workforce}

The next set of analyses was conducted to find out adaptive strategies employed by the management to address the $21^{\text {st }}$-century workforce. As earlier discussed, the administration projects retirement of older faculty members thus hiring younger but qualified teachers have been inevitable. Alongside this practice, it was deemed necessary to understand strategies that are in place to adapt to the $21^{\text {st }}$-century workforce.

Findings indicated a consensus that training and workshops have been organized to address the emerging needs of younger faculty members which "bridge older and younger generations of employees."

\subsection{Talent and Evaluation System}

The last set of the evaluation was conducted to explore practices as regards to talent evaluation or appraisal system in the graduate school. Data deduced from the responses indicated that there is an "updated evaluation or appraisal system" in graduate school. This result implies that performance as a key factor in overall organizational success is viewed by the administration as a significant element in management.

\section{Conclusions}

Based on the patterns of statements analyzed, the following conclusions are formulated:

1. Workforce demographics are well analyzed in graduate school. Age shift and retirement of faculty members play a major role in policy formulation. Competencies and staff needs are well considered as well as succession vision of the administration.

2. Awards and recognition systems, as well as flexible working schedules, are considered successful determinants for both recruitment and retention in the unit. From the students' point of view, the change in curricular landscape, as well as the nurturing nature of coaching and mentoring, has also indicated positive impacts on the management.

3. Training and seminars as related learning experience proved to be an effective strategy in bridging the gap between older and $21^{\text {st }}$-century generation employees.

4. The provision of a system for updated performance evaluation has boosted both teachers' and students' performance. This has led to greater productivity and output

\section{Recommendation}

The following recommendations are advance based on the formulated conclusions:

1. Since competency assessment is only done for current employees, identification of skills for future faculty members shall be given enough attention to create a vivid projection of the curricular programs and projects attainment.

2. Retention of quality workers is key to organization success, hence it is imperative that other strategies be explored to attract highly qualified faculty in the system and promote their retention in the highest educational unit in the university.

3. Employee engagement in all curricular activities shall be promoted since it bridges the link between retention and productivity.

\section{References}

1. Impact of talent management on the performance of an organization with special reference to ABG, Pipapav, Bharati 
ShipBuildingIndustries. [cited2012Nov].http://www.dypatil. edu/schools/management/wp-content/uploads/2015/11/ IMPACT-OF-TALENT-MANAGEMENT-ON-THEPERFORMANCE-OF-AN-ORGANIZATION-WITHSPECIAL-REFERENCE-TO-ABG-PIPAPAV-BHARATISHIPBUILDING-INDUSTRIES-Shruti-Naik.pdf.

2. Beyond HR: the new science of human capital. [cited 2007 Oct 05]. https://www.amazon.in/ Beyond-HR-Science-Human-Capital/dp/142210415X.

3. Collings DG, Mellahi K. Strategic talent management: a review and research agenda. Hum Resour Manag Rev. 2009;19:304-13.

4. Groysberg B, Sant L, Abrahams R. When "stars" migrate, do they still perform like stars? MIT Sloan Manag Rev. 2008;50:41-46.
5. Lewis RE, Heckman RJ. Talent management: a critical review. Hum Resour Manag Rev. 2006;16:139-54.

6. McDonnell A. Still fighting the "war for talent"? Bridging the science versus practice gap. J Bus Psychol. 2011;26:169-73.

7. Dries N, Pepermans R. Real high-potential careers: an empirical study into the perspectives of organizations and high potentials. Pers Rev. 2008;37(1):85-108.

8. Glenn T. The state of talent management in Canada's public sector. Can Public Adm. 2012;55(1):25-51.

9. Gallardo-Gallardo E, Nijs S, Dries N, Gallo P. Towards an understanding of talent management as a phenomenondriven field using bibliometric and content analysis. Hum Resour Manag Rev. 2015;25:264-79. 